\title{
Study on the Impact of FTA Agreement on Iceland- China Aquatic Products Trade Competitiveness: Data Validation from 2014 to 2018
}

\author{
Junyue Xie* \\ Center of Internet and Industrial Innovation Development \\ Research \\ Wenhua College \\ Wuhan, China \\ 3532026370@qq.com
}

\author{
Ming Yuan \\ City University of HongKong \\ HongKong
}

\begin{abstract}
This paper uses FTA terms of trade as a control variable to analyze the trade situation of Icelandic aquatic products exported to China after the entry into force of the China-Africa FTA Agreement. Compared with Norway, a reference country that has not signed the FTA agreement, it has adopted the dominant comparative advantage index and intraindustry trade. The calculation of the index reveals whether the target country and China have the impact of FTA terms of trade on their trade status. Comparative studies show that the trade of China-Aquatic aquatic products tends to be complementary rather than competitive. After the signing of the China-Africa FTA, the competitiveness of Icelandic aquatic products trade is gradually increasing. The share of Norwegian exports of aquatic products to China by non-FTA partners will gradually shift to Iceland. This confirms the enormous facilitation of the free trade agreement on both parties.
\end{abstract}

Keywords-aquatic product trade; free trade agreement; dynamic comparative advantage index

\section{OVERVIEW OF TRADE IN AQUATIC PRODUCTS BETWEEN CHINA AND ICELAND}

A. Overview of trade in aquatic products between China and Iceland

Iceland's aquaculture industry is developed and its production capacity is high. For a long time, the trade in aquatic products between China and Iceland has been in a state of deficit, and China's export advantage to Iceland' s aquatic products is weak. From 2008 to 2012, except for China's exports of Icelandic aquatic products to nearly US\$60,000 in 2009, the export value for the rest of the year was 0. After China Ice signed the FTA, the total import and export volume of China-Iceland bilateral cargo trade increased in 2015. Among them, Iceland's total exports of aquatic products to China increased by $60.5 \%$ year-on-year. As of 2017, the import and export volume of Sino-Ice bilateral goods was US\$540 million, an increase of $13.4 \%$ year-on-year. The scale of trade between China and Iceland is constantly expanding and is still developing steadily.
TABLE I. CHINA'S IMPORTS OF AQUATIC PRODUCTS TO ICELAND FROM SEPTEMBER 2008 TO SEPTEMBER 2016 AND TOTAL EXPORTS FROM ICELAND TO CHINA

\begin{tabular}{ccccc} 
Years & $\begin{array}{c}\text { China } \\
\text { exports } \\
\text { aquatic } \\
\text { products to } \\
\text { Iceland }\end{array}$ & $\begin{array}{c}\text { China's } \\
\text { total } \\
\text { exports to } \\
\text { Iceland }\end{array}$ & $\begin{array}{c}\text { China } \\
\text { imports } \\
\text { aquatic } \\
\text { products to } \\
\text { Iceland }\end{array}$ & $\begin{array}{c}\text { Unit: 10,000 USD } \\
\text { China's } \\
\text { total } \\
\text { imports to } \\
\text { Iceland }\end{array}$ \\
\hline 2008 & $\mathbf{0}$ & $\mathbf{9 3 1 3 . 7 4}$ & 3016.77 & 3510.58 \\
2009 & $\mathbf{5 . 7 6}$ & $\mathbf{5 4 2 1 . 7 0}$ & $\mathbf{2 5 5 2 . 4 5}$ & $\mathbf{3 3 2 5 . 2 8}$ \\
2010 & $\mathbf{0}$ & $\mathbf{7 1 0 0 . 7 7}$ & $\mathbf{2 8 1 7 . 4 0}$ & $\mathbf{4 1 3 1 . 9 8}$ \\
2011 & $\mathbf{0}$ & $\mathbf{7 6 5 8 . 0 8}$ & $\mathbf{6 5 0 3 . 6 6}$ & $\mathbf{7 5 5 9 . 9 0}$ \\
2012 & $\mathbf{0}$ & $\mathbf{9 5 3 8 . 8 0}$ & $\mathbf{6 2 5 2 . 6 6}$ & $\mathbf{8 8 9 6 . 0 9}$ \\
2013 & $\mathbf{5 2 . 6 7}$ & $\mathbf{1 4 3 7 6 . 0 0}$ & $\mathbf{5 0 8 1 . 7 0}$ & $\mathbf{7 5 7 9 . 9 1}$ \\
2014 & $\mathbf{6 . 6 6}$ & $\mathbf{1 2 5 0 2 . 0 0}$ & $\mathbf{4 1 7 2 . 9 0}$ & $\mathbf{5 9 7 1 . 7 6}$ \\
2015 & $\mathbf{1 9 . 7 1}$ & $\mathbf{3 8 0 0 0 . 0 0}$ & $\mathbf{4 8 3 5 . 3 0}$ & $\mathbf{6 5 9 6 . 6 6}$ \\
2016 & $\mathbf{2 0 0 . 0 0}$ & $\mathbf{3 9 0 0 0 . 0 0}$ & $\mathbf{6 9 6 9 . 0 0}$ & $\mathbf{9 1 0 1 . 0 0}$ \\
2017 & $\mathbf{0}$ & $\mathbf{4 4 7 0 0 . 0 0}$ & $\mathbf{7 1 5 8 . 0 0}$ & $\mathbf{9 7 0 0 . 0 0}$ \\
$2018(1-6$ & $\mathbf{0 . 0 1}$ & $\mathbf{2 9 0 0 . 0 0}$ & $\mathbf{4 9 6 2 . 0 0}$ & $\mathbf{6 6 7 7 . 0 0}$ \\
month) & & & & \\
\hline \multicolumn{5}{c}{ Source of data: According to the data of the Ministry of Commerce's "Country Report" }
\end{tabular}

As can be seen from TABLE I, China's total exports to Iceland far exceed China's total imports to Iceland, while China's total exports of fish to Iceland account for a small proportion of China's total exports to Iceland. In 2017, China's total exports to Iceland were four times that of 2008,indicating that China's total export volume has increased, but the export competitiveness of aquaculture industry is still small, and the growth rate of water industry exports is smaller than that of China's export trade. Both the import of aquatic products and the import trade of China showed an increasing trend. We can analyze that from 2008 to September 2016, China's imports of aquatic products to Iceland accounted for almost $70 \%$ of total imports, which is very different from the proportion of aquatic products exports (close to $0 \%$ ). China's aquatic products to Iceland have shown an upward trend since 2013, indicating that after the establishment of the China-Ice Free Trade Zone, the trade in aquatic products between China and Iceland has stabilized and rapidly compared to the period from 2008 to 2012. The rising state. 
B. Structure of aquatic products trade between China and Iceland

TABLE II. CHINA'S EXPORTS OF VARIOUS AQUATIC PRODUCTS TO ICELAND IN 2009-2015

\begin{tabular}{ccccc}
\hline Year & 034 & 035 & 036 & 037 \\
\hline 2009 & $100 \%$ & $0 \%$ & $0 \%$ & $0 \%$ \\
2010 & $0 \%$ & $0 \%$ & $0 \%$ & $0 \%$ \\
2011 & $0 \%$ & $0 \%$ & $0 \%$ & $0 \%$ \\
2012 & $0 \%$ & $0 \%$ & $0 \%$ & $0 \%$ \\
2013 & $0 \%$ & $0 \%$ & $100 \%$ & $0 \%$ \\
2014 & $0 \%$ & $0 \%$ & $100 \%$ & $0 \%$ \\
2015 & $50.79 \%$ & $49.21 \%$ & $0 \%$ & $0 \%$ \\
\hline
\end{tabular}

As can be seen from TABLE II, the amount of aquatic products exported from China to Iceland is very small. From 2010 to 2012, among the four major categories, China did not export aquatic products to Iceland at all, and in the following years there was a very small amount of exports, which was unevenly distributed. This shows that China's exports of aquatic products to Iceland are small and relatively scattered. It can be seen that although China's exports of aquatic products are large, Iceland has shown a weak export situation, and Iceland's aquatic products are more complementary to the Chinese aquatic products market.

\section{The particularity of the signing of the medium ice FTA agreement}

The signing of the FTA agreement in China Ice is unique. Iceland's land area is small, its national strength is limited, and its distance from China is far away. The economic and trade cooperation between the two countries is mainly based on complementary cooperation rather than competitive economic model. For China, Iceland has rich fishery resources and advanced level of aquatic product processing technology. While exporting a large number of resource-based products to China, it also continuously drives the adjustment and optimization of China's aquaculture structure and expands its industrial scale. At present, China has already tried to raise saltwater salmon in Qinghai and cultivate freshwater salmon in Qiandao Lake, hoping to achieve import substitution in the salmon market.

\section{MEASUREMENT OF TRADE COMPETITIVENESS OF AQUATIC PRODUCTS BETWEEN CHINA AND ICELAND}

\section{A. Model construction and data sources}

Based on the dynamic comparative advantage trade theory analysis framework, this paper uses the Revealed Comparative Advantage Index (RCA) to measure the importance of Iceland's aquatic product exports in its total export value, and uses the trade bond index TI to measure China and Iceland's exports. Structural differences in aquatic products.

\section{B. Analysis of Trade Index between China and Iceland's Aquatic Products Trade Relations}

1) $R C A$

The dominant comparative advantage index (RCA) has the expression:

$$
R C A_{\mathrm{ij}}=\frac{X_{i j} / \sum_{i} X_{i j}}{\sum_{j} X_{i j} / \sum_{j} \sum^{j} X_{i j}}
$$

TABLE III. 2008-2018 JUNE CHINA AND ICELAND'S TOTAL EXPORTS OF AQUATIC PRODUCTS IN THE COUNTRY ACCOUNTED FOR

\begin{tabular}{ccc}
\hline Year & China & Iceland \\
\hline 2008 & $0.74 \%$ & $32.27 \%$ \\
2009 & $0.89 \%$ & $36.75 \%$ \\
2010 & $0.88 \%$ & $35.33 \%$ \\
2011 & $0.93 \%$ & $34.39 \%$ \\
2012 & $0.92 \%$ & $35.52 \%$ \\
2013 & $0.92 \%$ & $36.67 \%$ \\
2014 & $0.93 \%$ & $35.06 \%$ \\
2015 & $0.89 \%$ & $34.04 \%$ \\
2016 & $0.95 \%$ & $33.60 \%$ \\
2017 & $0.40 \%$ & $37.70 \%$ \\
$2018(1-6)$ & $0.30 \%$ & $35.10 \%$ \\
\hline
\end{tabular}

Source of data: According to the data of the Ministry of Commerce's "Country Report"

Assume that the world trade volume of aquatic products trade and the world total of goods exports are X. As can be seen from TABLE III, China' $s$ exports of aquatic products account for about $1 \%$ of total exports, and Iceland' $\mathrm{s}$ exports of aquatic products are in total exports. The proportion is over $30 \%$. Therefore, Iceland has an advantage in the trade of aquatic products. In the past ten years, China's aquatic products have shown a downward trend in total domestic exports. The reason is that after China' s accession to the WTO, the trade export structure has undergone major changes, and it is upgrading from the traditional agricultural primary products and their processed manufactured exports to manufacturing. Export structure with service trade as the main export; with the improvement of environmental protection requirements, the domestic development of restorative aquatic product resources, objectively imposes environmental constraints on China's aquatic product exports, but the Chinese market is increasingly demanding aquatic products. Therefore, you must choose imported goods to meet the consumption upgrade.

2) Trade Integration Index (TI)

The trade union index (TI) used in this paper is expressed as:

$$
T I_{i h}=\frac{X_{i h} / X_{i}}{M_{h} / M_{w}}
$$




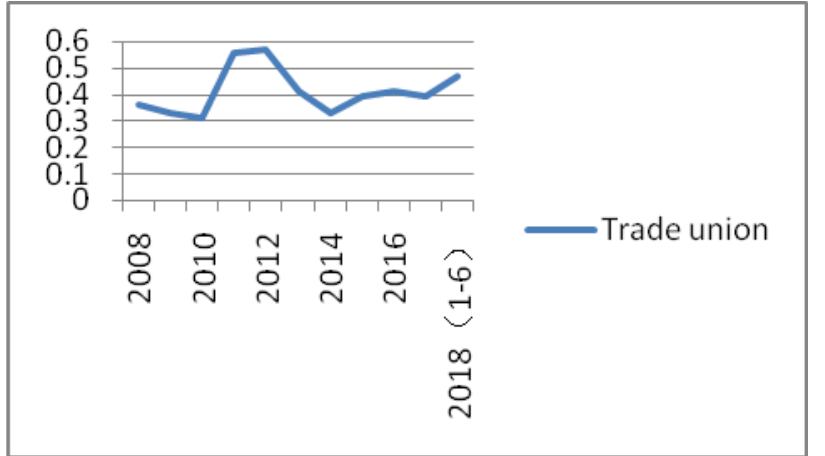

Source of data: According to the data of the Ministry of Commerce's "Country Report"

Fig. 1. 2008-2016 October China and Iceland Aquatic Products Trade Integration Index

As can be seen from TABLE IV, before 2010, trade in aquatic products between China and Iceland remained in the range of 0.3 to 0.6 . This shows that the trade relationship between the two countries is relatively distant. China is not the main import and export country of Icelandic aquatic products. From 2008 to October 2016, the degree of integration index fluctuated more obviously. The trade integration index in 2011 and 2012 was close to 0.6 , indicating that the trade in aquatic products between the two countries expanded in the past two years and the exchanges were closer, but in 2013, The environmental impact has dropped significantly. Since 2014, the status has rebounded and the TI index has increased.

\section{Analysis of the impact of medium ice FTA on each other's aquatic products trade}

1) Intra-industry trade model

The intra-industry trade (IIT) formula is:

$$
T=1-\frac{\left|X_{i}-M_{i}\right|}{X_{i}+M_{i}}
$$

This paper classifies aquatic products according to the WTO classification standard (SITC Rev.3) and calculates the domestic trade index of China and Iceland's aquatic products based on China's import and export data. The results are shown in TABLE IV.

TABLE IV. CHINA-ICELAND INTRA-INDUSTRY TRADE INDEX 2009-2015

\begin{tabular}{cccccc}
\hline Year & 034 & 035 & 036 & 037 & 03 \\
\hline 2009 & 0.03 & 0 & 0 & 0 & 0.004 \\
2010 & 0 & 0 & 0 & 0 & 0 \\
2011 & 0 & 0 & 0 & 0 & 0 \\
2012 & 0 & 0 & 0 & 0 & 0 \\
2013 & 0 & 0 & 0.63 & 0 & 0.02 \\
2014 & 0 & 0 & 0.06 & 0 & 0.003 \\
2015 & 0.05 & 0.28 & 0 & 0 & 0.03 \\
\hline \multicolumn{7}{c}{ Source of data: According to the data of the Ministry of Commerce's "Country Report" }
\end{tabular}

From a horizontal comparison (as shown in TABLE IV), the higher index of intra-industry trade in China's Icelandic aquatic products industry is 036 (crustaceans), followed by 035 (dried, salted or salted fish, smoked fish) . But overall, the index of all categories is low, and intra-industry trade is not developed. From 2010 to 2012, the index is 0, which is a complete inter-industry trade, indicating that China's Icelandic aquaculture industry only has import trade or export trade. In other years, although different types of products have different levels of intra-industry trade, the data is very small, indicating that inter-industry trade is the main trade method of aquatic products in China and Iceland.

From a vertical comparison, from 2009 to 2015, 037 (other aquatic products) has been the state of inter-industry trade, and 035 (dried, salted or salted fish, smoked fish) began intraindustry trade in 2015, 034 (Fresh, cold, frozen fish fillets and other fish) have risen. Except for 036 (crust mollusks), which has been completely converted into inter-industry trade, although other intra-industry trade indexes are very small, the situation has improved.

Overall, the intra-industry trade measurement index has smaller data and more scattered distribution, indicating that China's Icelandic intra-industry trade is not developed, indicating that the aquatic products trade between the two countries is more complementary. Since the bilateral implementation of the free trade agreement in 2014, we can see that the trade situation is slowly improving, but the trend of index increase is not significant. From the perspective of product structure, China's aquatic product export competitiveness is more reflected in low-end products, and Iceland's trade competitiveness advantage is reflected in highend products. For example, in China's domestic salmon consumption market, chilled salmon originating in Iceland gradually occupied a high-end market share. It can be predicted that as the tariffs on aquatic products in the two countries are reduced to zero, the aquatic products market in China and Iceland will further expand trade cooperation, and the trade scale and trade specialization level will be further developed.

\section{ICELAND AND NORWAY - COMPARATIVE ANALYSIS OF TRADE CONDITIONS WITH OR WITHOUT FTA}

According to the comparison of the trade degree between China and Norway, this paper finds that the trade degree of aquatic products between China and Norway is less than 1, indicating that the trade integration between the two countries is not high. China and Norway are far apart from each other. Due to differences in politics and culture, trade between China and Norway is small and not stable enough. In terms of horizontal comparison, after 2008, the trade integration between Norway and China has made a big breakthrough, showing an upward trend in fluctuations. Until 2014, the trade integration index fell more obviously. It shows that after 2014, the trade of aquatic products between China and Norway has been greatly adversely affected, but it also shows that the potential of aquatic products trade between the two countries is huge and there is still much room for development. 


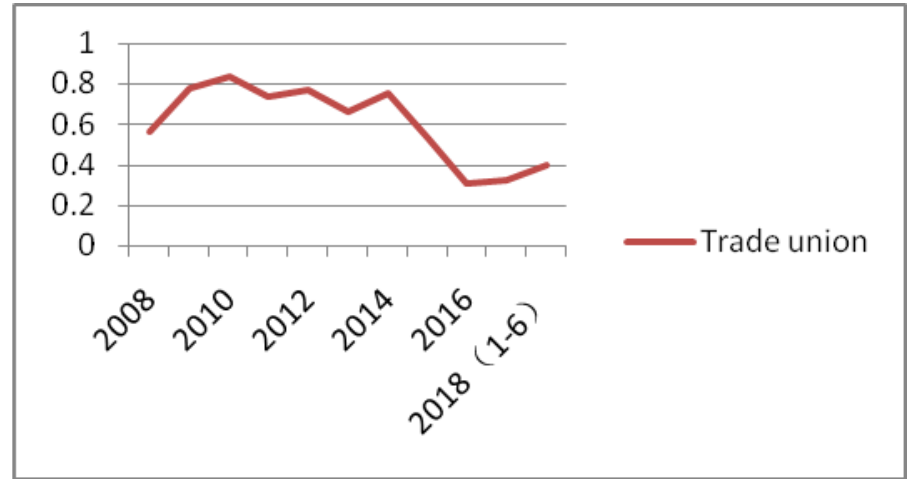

Source of data: According to the data of the Ministry of Commerce's "Country Report"

Fig. 2. 2008-2016 October China and Norway Aquatic Products Trade Integration Index

The overall situation is divided into two stages: before the establishment of the free trade zone in China's Iceland in 2014, the trade integration between China and Norway was much higher than that of China, but in 2010, due to political events, China was caused. The suspension of the Norwegian Free Trade Area negotiations, the trade volume of fish products between Norway and China has dropped significantly. In the same year, the integration of aquatic products trade in China's Iceland increased. After the establishment of the free trade zone in Iceland in 2014, the trade integration between China and Norway fell sharply. In 2016, it was lower than the trade integration degree of China's Iceland. It is very likely that the trade transfer effect caused by the establishment of the free trade zone. Part of the trade in aquatic products between China and Norway was transferred to Iceland. The establishment of a free trade zone in Iceland has played a good demonstration role for China and Norway to establish an FTA, and has improved the feasibility of establishing an FTA between China and Norway.

\section{EMPIRICAL ANALYSIS}

a. China and Iceland FTA sign the trade expansion effect and transfer effect

b. The impact of the big country effect will expand the scale of China's aquatic products trade

c. The dependence of aquatic products trade between China and Iceland will show a clear upward trend

China is a big importer of aquatic products. In recent years, the Chinese people's demand for high-quality aquatic products has been rising. It can be predicted that Chinese consumers will shift from ordinary, lower-quality aquatic products to distinctive, high-quality aquatic products, indicating that China will have huge market potential for overseas imported aquatic products. Under the framework of the FTA between China and Iceland, the implementation of zero tariffs on aquatic products in China and Iceland will greatly boost the trade in aquatic products between China and Iceland. As
China's import of Icelandic aquatic products continues to expand, China's influence on the international aquatic products market can be controlled to control import costs, resulting in better price advantages. At the same time, as China's cooperation with Iceland promotes the continuous upgrading of China's aquaculture industry, the big country effect will also expand China's aquatic product export trade, indicating that China's aquatic product trade has great potential.

\section{CONCLUSIONS AND PROSPECTS}

Since 2018, the trade disputes provoked by the United States have cast a shadow over the development of international trade under economic globalization. China holds high the banner of free trade, cooperation and win-win, and acts as a trustworthy partner in global economic and trade relations. The cooperation of China Ice FTA has become a vivid example of trade cooperation between China and European countries and seeking a win-win situation.

The pursuit of a better life in China's domestic people is reflected in the consumer market, that is, the per capita income rises and the consumption structure continues to escalate. In international trade, China's demand for imported goods expands significantly, which is particularly prominent in the high-end aquatic product consumer market. . Looking to the future, China is the world's second largest economy with a vast market of nearly 1.4 billion people. As China's cooperation with Iceland continues to deepen, Iceland will benefit more from trade cooperation with China. This will serve as a model for China's future international trade cooperation with other European countries at the FTA Free Trade Agreement level.

\section{REFERENCES}

[1] Chunlin Cai.Analysis of the Impact of the Establishment of China-Bing Free Trade Zone on China's Aquaculture Industry and Countermeasures[C].2008 Proceedings of China Fisheries Economic Experts Forum, Beijing, 2008, 215-219. (In Chinese)

[2] Siyuan Zhai, Jintian Gao. The Impact of China Ice Free Trade Zone on China's Aquatic Products Import Trade[J]. China Fisheries Economics, 2015, (2): 36-43. (In Chinese)

[3] Chunlin Cai. A New Platform for Mutual Benefit and Win-Win Situation-Establishing the Impact of Free Trade Zones of China Ice, China, Norway, China and New Zealand on China's Aquaculture Industry and Its Countermeasures[J].International Trade,2008,(3) :3741.(In Chinese)

[4] Thor Sigfusson, Karyn Morrissey, Ragnar Arnason. The economic importance of the Icelandic fisheries cluster-Understanding the role of fisheries in a small economy.[J].Marine Policy.2013.39(2013)154-16 Business Administration.2014.(In Chinese)

[5] Thor Sigfusson, Karyn Morrissey, Ragnar Arnason. The economic importance of the Icelandic fisheries cluster-Understanding the role of fisheries in a small economy.[J].Marine Policy.2013.39(2013)154-16.(In Chinese)

[6] Hugo Miguel Borges Esteves. Which sectors of the Icelandic economy are likely to benefit the most after the Free Trade Agreement with China?[D]Business Administration.2014.(In Chinese) 